\title{
Combined endoscopic and surgical management of small-bowel polyposis in a patient with Peutz-Jeghers syndrome
}

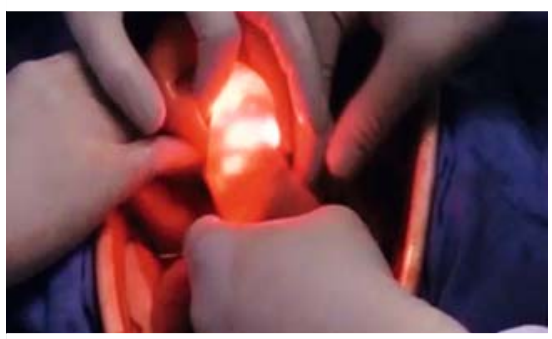

- Fig. 1 Surgical view of the "clean sweep" technique, with the colonoscope being surgically advanced by plicating the bowel over the scope.

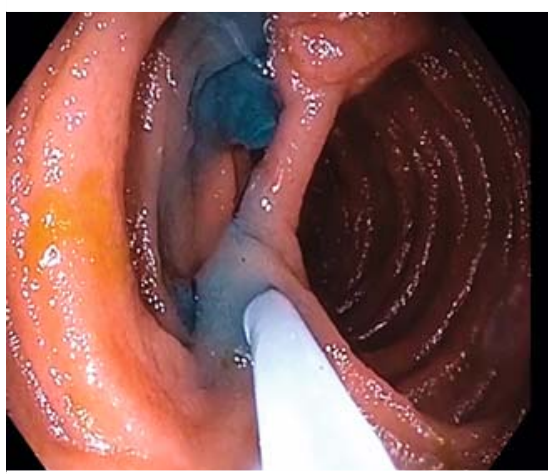

Fig. 2 Endoscopic view of the "clean sweep" technique for small-bowel polypectomy.

Peutz-Jeghers syndrome (PJS) is a hereditary condition characterized by hamartomatous polyps throughout the gastrointestinal tract, typically in the small bowel and colon [1,2]. PJS carries an increased cancer risk and requires lifelong surveillance in order to detect polyps that may cause both intussusception/obstruction and cancer [1,2].

A "clean sweep" is a combined endoscopic and surgical procedure for the management of small-bowel polyps in PJS [3]. At laparotomy, the surgeon telescopes the endoscope over the small bowel with subsequent endoscopic/sur-

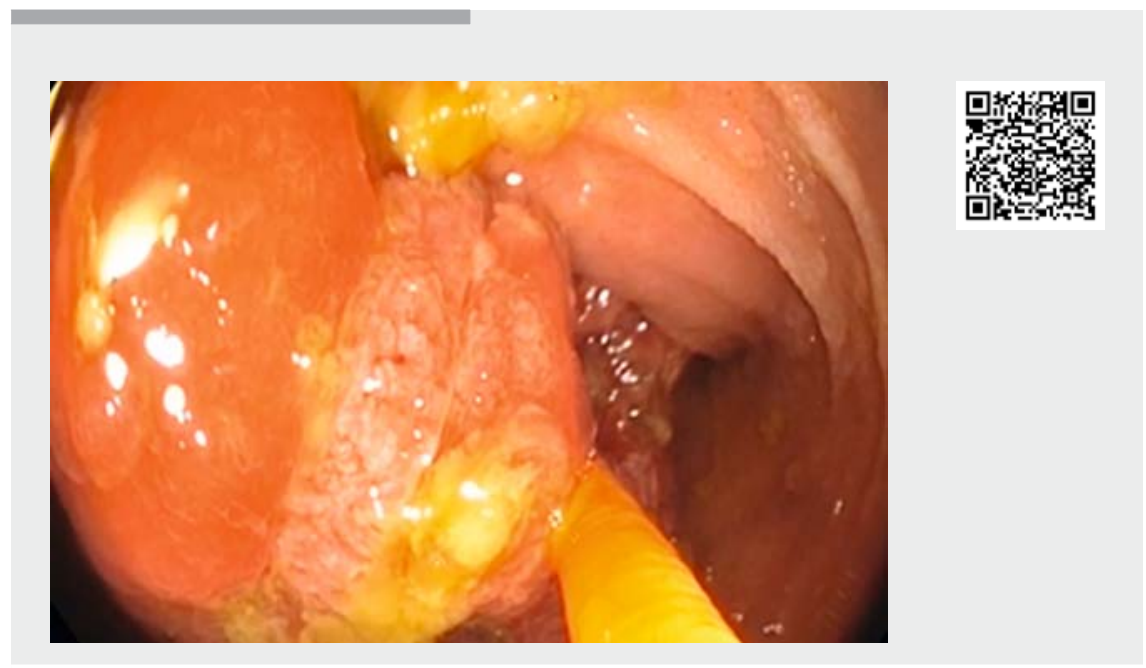

$\checkmark$ Video 1 Management of a significant polyp burden in a 55-year-old man with PeutzJeghers syndrome using the combined surgical and endoscopic "clean sweep" technique.

gical polypectomy, minimizing the need for bowel resection and reducing the risk of short-gut syndrome [3].

This video describes the management of significant polyp burden in a 55-year-old man with PJS ( $\triangleright$ Video 1 ) who had undergone two previous laparotomies for small-bowel obstruction and multiple enterotomies for polypectomy.

Initial colonoscopy confirmed a partially obstructing polypoid mass in the distal ileum. Endoscopic submucosal dissection of the polyp stalk was performed but further dissection revealed two feeding arteries and a thick muscular band, which prevented further dissection. Hemoclips were placed on the arteries in an attempt to necrose the lesion.

Following discussion with the gastroenterology and colorectal surgery services, repeat colonoscopy was planned in the operating room. If the polyp was not necrosed, endoscopic dissection would be re-attempted, with rescue conversion to surgical resection if necessary. On en- doscopy, the mass was not necrotic but the submucosal plane could not be easily identified, preventing safe endoscopic dissection.

The procedure was converted to a surgical resection, but this revealed multiple polyps more proximally throughout the small bowel. To clear the remaining small-bowel polyps, a clean sweep was performed. A pediatric colonoscope was introduced orally and advanced distally to the ileal anastomosis by plicating the bowel over the scope ( $\triangleright$ Fig.1). About 50 polypectomies were then performed using endoscopic mucosal resection (> Fig. 2).

At the 3-month follow-up, magnetic resonance enterography identified no highrisk polyps in the small bowel. The combination of endoscopy and surgery allowed effective management of the obstructing ileal polyp and overall polyp burden.

Endoscopy_UCTN_Code_TTT_1AT_2AF 
None

The authors

Feng Li ${ }^{1}$, Neal Mehta ${ }^{1}$, David Liska², Beatrice Dionigi ${ }^{2}$, Matthew F. Kalady ${ }^{2}$, Carol A. Burke ${ }^{1}$, Amit Bhatt ${ }^{1}$

1 Department of Gastroenterology, Hepatology and Nutrition, Cleveland Clinic Foundation, Cleveland, Ohio, United States

2 Department of Colorectal Surgery, Cleveland Clinic Foundation, Cleveland, Ohio, United States

\section{Amit Bhatt, MD}

Department of Gastroenterology,

Hepatology, and Nutrition, Cleveland Clinic

Main Campus, Mail Code A31, 9500 Euclid

Avenue, Cleveland, $\mathrm{OH}$ 44195, United States

Fax: +1-216-444-6284

Bhatta3@ccf.org

\section{References}

[1] Beggs AD, Latchford AR, Vasen HFA et al. Peutz-Jeghers syndrome: a systematic review and recommendations for management. Gut 2010; 59: 975-986

[2] Utsunomiya J, Gocho H, Miyanaga T et al. Peutz-Jeghers syndrome: its natural course and management. Johns Hopkins Med J 1975; 136: $71-82$

[3] van Coevorden F, Mathus-Vliegen EM, Brummelkamp WH. Combined endoscopic and surgical treatment in Peutz-Jeghers syndrome. Surg Gynecol Obstet 1986; 162: $426-428$
Bibliography

DOI https://doi.org/10.1055/a-1011-4122

Published online: 27.9.2019

Endoscopy 2020; 52: E102-E103

(c) Georg Thieme Verlag KG

Stuttgart · New York

ISSN 0013-726X

\section{ENDOSCOPY E-VIDEOS}

https://eref.thieme.de/e-videos

回回 Endoscopy E-Videos is a free w access online section, reporting 回些: on interesting cases and new techniques in gastroenterological endoscopy. All papers include a high quality video and all contributions are freely accessible online.

This section has its own submission website at

https://mc.manuscriptcentral.com/e-videos 